\title{
MINERALOGIA E TEORES DE CROMO, NÍQUEL, COBRE, ZINCO E CHUMBO NOS SOLOS NO ENTORNO DO ATERRO SANITÁRIO DA CAXIMBA EM CURITIBA-PR ${ }^{1}$
}

\author{
MINERALOGY AND CHROMIUM, NICKEL, COPPER, ZINC AND LEAD \\ CONTENTS AROUND CAXIMBA LANDFILL IN CURITIBA-PR
}

\author{
Sonia ZANELLO ${ }^{2}$ \\ Vander de Freitas MELO ${ }^{3}$ \\ Gisele Inês Taraszkiewecz Harbar WOWK ${ }^{4}$
}

\begin{abstract}
RESUMO
Sete perfis de solos do entorno do Aterro Sanitário da Caximba em Curitiba-PR, foram coletados para caracterização e quantificação dos minerais da fração argila e determinação dos teores totais e trocáveis de $\mathrm{Cr}, \mathrm{Ni}, \mathrm{Cu}, \mathrm{Zn}$ e $\mathrm{Pb}$. A fração argila foi estudada por difratometria de raios- $X$, análise térmica e extrações químicas com oxalato de amônio, ditionito-citratobicarbonato de sódio. Os teores totais e trocáveis dos metais pesados foram determinados nas amostras de solo por espectroscopia de absorção atômica, após digestão ácida $\left(\mathrm{H}_{2} \mathrm{SO}_{4}, \mathrm{HF}, \mathrm{HNO}_{3}\right.$ e $\mathrm{HClO}_{4}$ concentrados) e extração com solução de $\mathrm{BaCl}_{2} 1 \mathrm{~mol} \mathrm{dm}^{-3}$, respectivamente. O predomínio de caulinita, com teores variando de 548,5 a $702,1 \mathrm{~g} \mathrm{~kg}^{-1}$, e a ocorrência de vermiculita com hidroxi entre camadas na fração argila determinaram os relativamente altos valores de CTC dos solos. Os teores de óxidos de Fe foram baixos, evidenciando a natureza do material de origem (granito/ganisse e sedimentos argilosiltosos) e as condições de redução e remoção de Fe para os solos sob influência de hidromorfismo. De maneira geral, verificou-se incremento nos teores de metais pesados nos solos do entorno do aterro sanitário. Contudo, o nível de contaminação não foi muito expressivo, relacionado às baixas concentrações de $\mathrm{Cr}$, $\mathrm{Ni}, \mathrm{Cu}, \mathrm{Zn}$ e $\mathrm{Pb}$ no chorume; facilidade de lixiviação nos solos hidromórficos e; altos teores de cátions divalentes e trivalentes $\left(\mathrm{Ca}^{2+}, \mathrm{Mg}^{2+}\right.$ e $\left.\mathrm{Al}^{3+}\right)$ no complexo sortivo dos solos.
\end{abstract} pesados.

Palavras-chave: caulinita; vermiculita com hidroxi entre camadas; óxidos de $\mathrm{Fe}$ e Al; contaminação por metais

\begin{abstract}
Seven soil profiles were collected around Caximba Landfill, in Curitiba - PR, to characterize and quantify clay fraction mineral and to determine total and exchangeable $\mathrm{Cr}, \mathrm{Ni}, \mathrm{Cu}, \mathrm{Zn}$ and $\mathrm{Pb}$ contents. Clay Fraction was studied by $\mathrm{x}$-ray diffractometry (XRD), thermal analysis and chemical extractions with ammonium oxalate $(A O)$ and sodium dithionite-citratebicarbonate (DCB). Heavy metals total and exchangeable contents were determined by atomic absorption spectrophotometry, after sample acid digestion $\left(\mathrm{H}_{2} \mathrm{SO}_{4}, \mathrm{HF}, \mathrm{HNO}_{3}\right.$ e $\mathrm{HClO}_{4}$ concentrated) and extraction with $\mathrm{BaCl}_{2} 1 \mathrm{~mol} \mathrm{dm}^{-3}$, respectively. The predominance of kaolinite, which varied between 548,5 to $702,1 \mathrm{~g} \mathrm{~kg}^{-1}$, and the occurrence of vermiculite with hidroxi between layers in clay fraction, determined the soils relatively high CEC. Iron oxide contents were low, making the nature of the parent material evident (granite/gneiss and clay-silt sediments) and the Fe reduction conditions and removal to soils under hydromorphism influence. In a general way, increase of heavy metals contents around Caximba Landfill soil was observed. Although, contamination levels were not very expressive, related to the low concentrations of $\mathrm{Cr}, \mathrm{Ni}, \mathrm{Cu}, \mathrm{Zn}$ and $\mathrm{Pb}$ in leachate; leaching facility in hydromorphic soils; high divalent and trivalent cation contents $\left(\mathrm{Ca}^{2+}, \mathrm{Mg}^{2+}\right.$ e $\left.\mathrm{Al}^{+3}\right)$ in sorptive soil complexes.
\end{abstract}

Key-words: kaolinite; hidroxi interlayer vermiculite; Fe and Al oxides; heavy metal contamination.

1 Parte da Dissertação de Mestrado do primeiro autor.

2 Departamento de Química e Biologia, Universidade Tecnológica Federal do Paraná (UTFPR). Av. Sete de Setembro, 3165, Rebouças, CEP 80230-010, Curitiba - PR, Brasil. E-mail: zanello@utfpr.edu.br.

3 Departamento de Solos e Engenharia Agrícola, Universidade Federal do Paraná (UFPR). Rua dos Funcionários, 1540, CEP: 80035-050, Curitiba - PR, Brasil. Bolsista CNPq. E-mail: vanderfm@ufpr.br. Autor para correspondência.

4 Mestre em Ciência do Solo. Departamento de Solos e Engenharia Agrícola, Universidade Federal do Paraná. Rua dos Funcionários, 1540, CEP: 80035-050, Curitiba - PR, Brasil. E-mail: giselewowk@brturbo.com. 


\section{INTRODUÇÃO}

Nos últimos anos, ampliações emergenciais no Aterro Sanitário da Caximba, em Curitiba, Paraná, fizeram com que as lagoas de tratamento do chorume não suportassem mais os seus volumes crescentes. Boa parte do chorume não tratado é lançado diretamente em valetas que o conduzem diretamente ao Rio Iguaçu, encharcando os solos por onde passa e comprometendo a qualidade destes, das águas superficiais e subterrâneas e o abastecimento de vários municípios, como por exemplo, União da Vitória (MP. PR, 2004; Morais, 2005).

Segundo Alloway (1993) os metais pesados podem entrar na cadeia alimentar, acumular-se no solo, alterar a atividade microbiana, causar fitotoxidade e também contaminar os recursos hídricos. Dessa forma, constituir grande risco para a saúde de animais e seres humanos, por causar distúrbios em seus processos metabólicos.

O comportamento de metais pesados nos solos, provenientes de uma carga poluidora como chorume (Koh et al., 2004; Silva et al., 2004), é controlada por atributos físicos, químicos e mineralógicos dos solos (Kabata Pendias \& Pendias, 2001; Fontes et al., 2001), que definem suas diversas formas químicas (solúvel, precipitado, complexado e adsorvido). A retenção de cátions metálicos no solo é devida à capacidade de troca catiônica (CTC), seletividade do metal, concentração de outros cátions, $\mathrm{pH}$ e atividade iônica da solução. A fração argila e matéria orgânica humificada do solo apresentam tanto cargas positivas quanto negativas, normalmente, com predomínio de CTC. As cargas originadas da protonação e desprotonação dos grupamentos funcionais fenólicos $(-\mathrm{OH})$ e carboxílicos $(-\mathrm{COOH})$ da matéria orgânica, e grupamentos hidroxila $(\mathrm{OH})$ dos óxidos de Fe e Al e bordas de argilas silicatadas (principalmente minerais 1:1), manifestam-se de acordo com o pH meio (Sparks, 1995; Naidu et al., 1998). Nos minerais de argila silicatados do tipo 2:1 as cargas originamse em maior parte por substituição isomórfica de íns na rede cristalina. Desta forma, estas cargas são permanentes, assim, os cátions podem ser adsorvidos eletrostaticamente em qualquer valor de $\mathrm{pH}$ do solo.

A adsorção na superfície dos minerais de argila e da matéria orgânica do solo pode ser específica (complexo de esfera interna), onde a ligação metal-superfície hidroxilada apresenta alto caráter covalente (Sodré et al., 2001; Sparks, 1995), ou, não especifica (complexo de esfera externa ou atração eletrostática), o que facilita as reações de troca iônica devido a menor energia de retenção de metais pesados (Sparks, 1995). Complexos de esfera interna ocorrem mais comumente em minerais de argila com cargas $\mathrm{pH}$ dependentes, como a hematita, goethita, gibbsita e caulinita e complexos de esfera externa em minerais de argila com carga permanente, como as esmectitas e a vermiculita (Sparks, 1995; Naidu et al., 1998).

O objetivo deste trabalho foi estudar a mineralogia da fração argila dos solos do entorno do Aterro Sanitário da Caximba em Curitiba-PR, e determinar a concentração de metais pesados nos solos para averiguar se ocorreu incremento desses metais em decorrência da atividade do aterro.

\section{MATERIAL E MÉTODOS}

Realizou-se a amostragem em sete perfis de solos no entorno do Aterro Sanitário da Caximba (Figura 1) nas profundidades de 0 a 20; 20 a 40 e 40 a $60 \mathrm{~cm}$. Os solos amostrados foram classificados e descritos, como mostra a Tabela 1. Os perfis R1 e R2 (Cambissolo Háplico e Gleissolo Háplico, respectivamente), foram amostrados como referência para estabelecer os teores naturais de metais pesados nestas amostras supostamente livres de influência antrópica.

Foram coletadas amostras de chorume dos três emissários de líquidos percolados, referente às fases I, II e III do aterro, denominadas $\mathrm{CH} 1, \mathrm{CH} 2$ e $\mathrm{CH} 3$, respectivamente. No momento da amostragem de solo e chorume (2004), as fases I e II já estavam lacradas e a fase III ainda estava em atividade, recebendo o lixo da região metropolitana de Curitiba.

As análises químicas da terra fina seca ao ar (TFSA), como $\mathrm{pH}$, bases trocáveis, e acidez potencial, foram conduzidas segundo as metodologias apresentadas por EMBRAPA (1999b). Os teores de carbono orgânico e fósforo foram determinados por colorimetria conforme descrito em UFPR (2003).

A análise textural da TFSA foi determinada pelo método da pipeta (EMBRAPA, 1997).

As amostras de solo (TFSA) foram solubilizadas com ácidos concentrados $\left(\mathrm{HF}, \mathrm{HNO}_{3}\right.$, $\mathrm{H}_{2} \mathrm{SO}_{4}$ e $\mathrm{HClO}_{4}$ ), segundo o método de $\mathrm{Lim}$ \& Jackson (1986). Os teores totais de metais nos extratos foram determinados por espectrometria de absorção atômica (EAA) com chama ar-acetileno por equipamento Avanta GBC. Para determinação dos teores trocáveis de $\mathrm{Cr}, \mathrm{Ni}, \mathrm{Cu}, \mathrm{Zn}$ e $\mathrm{Pb}, 1 \mathrm{~g}$ de TFSA foi agitado com $30 \mathrm{~cm}^{3}$ de solução extratora de $\mathrm{BaCl}_{2}$ $0,1 \mathrm{~mol} \mathrm{dm}^{3}$ por $2 \mathrm{~h}$ (Gomes et al., 1997). A suspensão foi filtrada e a determinação dos teores de metais foi feita conforme descrito anteriormente.

Foi transferido $0,1 \mathrm{~cm}^{3}$ de cada amostra de chorume $(\mathrm{CH} 1, \mathrm{CH} 2$ e $\mathrm{CH} 3)$ para cadinho de teflon de $150 \mathrm{~cm}^{3}$, e feita a digestão ácida (Lim \& Jackson, 1986). A determinação dos teores totais de metais foi feita por EAA.

Para o estudo da mineralogia da fração argila dos solos, amostras de TFSA foram tratadas com peróxido de hidrogênio $\left(\mathrm{H}_{2} \mathrm{O}_{2}\right)$ a $30 \%$ para a oxidação da matéria orgânica (Kunze \& Dixon, 1986). O resíduo deste tratamento foi agitado por duas horas com solução de $\mathrm{NaOH} 0,2 \mathrm{~mol}^{2} \mathrm{dm}^{3}$ para dispersão das frações (Jackson, 1979). A fração areia foi retida em peneira de $0,053 \mathrm{~mm}$ e a suspensão de argila e silte foi recolhida em uma proveta de $1000 \mathrm{~cm}^{3}$. O volume das provetas foi completado com água deionizada para a separação das frações argila e silte por sedimentação com base na lei de Stokes (Gee \& Bauder, 1986). 
TABELA 1 - Material de origem, classificação dos solos e detalhes dos ambientes de amostragem.

\begin{tabular}{|c|c|c|c|}
\hline $\begin{array}{c}\text { Pontos de } \\
\text { Coleta }\end{array}$ & $\begin{array}{c}\text { Material de } \\
\text { origem }\end{array}$ & Classe $^{(3)}$ & Descrição \\
\hline $\mathrm{R} 1^{(1)}$ & $\begin{array}{l}\text { Granito } \\
\text { gnaisse }\end{array}$ & $\begin{array}{l}\text { Cambissolo } \\
\text { Háplico }\end{array}$ & $\begin{array}{l}\text { Fora dos limites e a montante do aterro. Seco, } \\
\text { supostamente sem influências antropogênicas. Altitude: } \\
913 \mathrm{~m} .\end{array}$ \\
\hline P1 & $\begin{array}{l}\text { Granito } \\
\text { gnaisse }\end{array}$ & $\begin{array}{l}\text { Antropossolo } \\
\text { Líxico }\end{array}$ & $\begin{array}{c}\text { Localiza-se próximo a borda da parte superior do aterro, } \\
\text { local de convergência de águas pluviais provenientes da } \\
\text { Fase I, em cota mais baixa que o perfil R1 e sem influência } \\
\text { direta do chorume superficial. Lençol freático elevado. } \\
\text { Altitude: } 908 \mathrm{~m} \text {. }\end{array}$ \\
\hline P2 & $\begin{array}{l}\text { Granito } \\
\text { gnaisse }\end{array}$ & $\begin{array}{l}\text { Antropossolo } \\
\text { Líxico }\end{array}$ & $\begin{array}{c}\text { A jusante do aterro, recebe águas pluviais oriundas da } \\
\text { Fase I, várzea típica do Rio Iguaçu com vegetação de } \\
\text { taboa, apresenta hidromorfismo e lixo miúdo, fragmentos } \\
\text { de plásticos, misturado aos sedimentos, nível freático } \\
\text { oscilante. Sem influência direta do chorume. Altitude: } 881 \\
\text { m. }\end{array}$ \\
\hline P3 & $\begin{array}{l}\text { Sedimentos } \\
\text { Argilo-siltosos }\end{array}$ & $\begin{array}{l}\text { Antropossolo } \\
\text { Líxico }\end{array}$ & $\begin{array}{l}\text { Além dos limites do aterro, a jusante deste, várzea típica } \\
\text { do Rio Iguaçu com vegetação de taboa, onde o córrego } \\
\text { afluente do Iguaçu está rico em chorume, apresenta } \\
\text { hidromorfismo e lixo miúdo, fragmentos plásticos, } \\
\text { misturado aos sedimentos. Solo visivelmente impregnado } \\
\text { com chorume e de odor intenso. Presença de agricultura } \\
\text { de subsistência, animais domésticos como bovinos e } \\
\text { eqüinos, nível freático oscilante. Altitude: } 872 \text { m. }\end{array}$ \\
\hline P4 & $\begin{array}{l}\text { Sedimentos } \\
\text { Argilo-siltosos }\end{array}$ & $\begin{array}{l}\text { Antropossolo } \\
\text { Líxico }\end{array}$ & $\begin{array}{c}\text { Ponto da várzea mais distante do aterro e mais próximo ao } \\
\text { Rio Iguaçu à margem de uma cava de extração de areia } \\
\text { desativada, leito maior do rio. Local sob influência direta do } \\
\text { chorume. Altitude: } 871 \mathrm{~m}\end{array}$ \\
\hline P5 & $\begin{array}{l}\text { Sedimentos } \\
\text { Argilo-siltosos }\end{array}$ & $\begin{array}{l}\text { Antropossolo } \\
\text { Líxico }\end{array}$ & $\begin{array}{c}\text { Margem do córrego oposta ao ponto P3 e sob mesmas } \\
\text { condições que este. Altitude: } 869 \mathrm{~m}\end{array}$ \\
\hline $\mathrm{R} 2^{(2)}$ & $\begin{array}{l}\text { Sedimentos } \\
\text { Argilo-siltosos }\end{array}$ & $\begin{array}{l}\text { Gleissolo } \\
\text { Háplico }\end{array}$ & $\begin{array}{l}\text { Ponto de várzea também próximo ao Rio lguaçu, inundado } \\
\text { durante todo o ano. Apresenta alto grau de hidromorfismo. } \\
\text { Sob influências do Rio Iguaçu no período de cheias. } \\
\text { Localiza-se a montante da área que recebe o chorume. } \\
\text { Altitude: } 879 \text { m. }\end{array}$ \\
\hline
\end{tabular}

${ }^{(1)}$ Solo de referência que representa os perfis P1 e P2; ${ }^{(2)}$ Solo de referência que representa os perfis P3, P4 e P5; ${ }^{(3)}$ EMBRAPA (1999 a) e Curcio et al. (2004).

Amostras da fração argila secas em estufa a $60{ }^{\circ} \mathrm{C}$ foram trituradas em almofariz de ágata e montadas em placas de Koch para identificação dos minerais por difração de raios-X (DRX), em difratômetro Philips, modelo PW1050/70 equipado com tubo de cobre, filtro de Ni, operando a $20 \mathrm{~mA}$ e $40 \mathrm{kV}$ e velocidade angular do goniômetro de $1{ }^{\circ} 2 \Theta$ $\mathrm{min}^{-1}$, numa amplitude de 4 a $65^{\circ} 2 \theta$.

Para determinar os teores e a composição química dos óxidos de $\mathrm{Fe}$ e $\mathrm{Al}$ de baixa cristalinidade e óxidos de $\mathrm{Fe}$ cristalinos foram utilizadas extrações com oxalato ácido de amônio $0,2 \mathrm{~mol} \mathrm{dm}^{3}, \mathrm{pH} 3,0$ (OA) (McKeague, 1978) e com ditionito-citratobicarbonato-de sódio (DCB) (Mehra \& Jackson, 1960), respectivamente, conforme detalhes apresentados por Melo et al. (2001b). Nos extratos, os teores de $\mathrm{Fe}$ e $\mathrm{Al}$ foram determinados por EAA. Os resíduos da extração com $D C B$ e OA foram secos em estufa ( $24 \mathrm{~h}$ em estufa a $105^{\circ} \mathrm{C}$ ) e pesados para determinação da perda de massa promovida pelas extrações.
Para diferenciar os minerais 2:1 da fração argila foram realizados tratamentos adicionais (Whittig \& Allardice, 1986) em amostras desferrificadas (tratadas com DCB): saturação com $\mathrm{Mg}$, saturação com $\mathrm{Mg}$ e solvatação com etileno glicol, saturação com $\mathrm{K}$ e secagem ao ar, saturação com K e secagem a $550{ }^{\circ} \mathrm{C}$ em mufla. Após os tratamentos, as amostras foram montadas em lâminas de vidro utilizando-se a técnica do esfregaço para obtenção de amostras orientadas e analisadas por DRX, numa amplitude de 3 a $15^{\circ} 2 \theta$.

A fração argila desferrificada também foi analisada termo-gravimetricamente pelo aquecimento de $20 \mathrm{mg}$ de amostra a partir da temperatura ambiente até $1.000^{\circ} \mathrm{C}$, numa taxa de

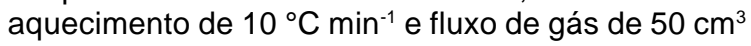
min $^{-1}$, sob atmosfera de $\mathrm{N}_{2}$. A interpretação qualitativa foi feita pelas características dos picos endotérmico e exotérmico dos minerais, e a quantificação da caulinita e gibbsita foi feita de acordo com a perda de massa da amostra, em decorrência da desidroxilação dos minerais (Jackson, 1979). 


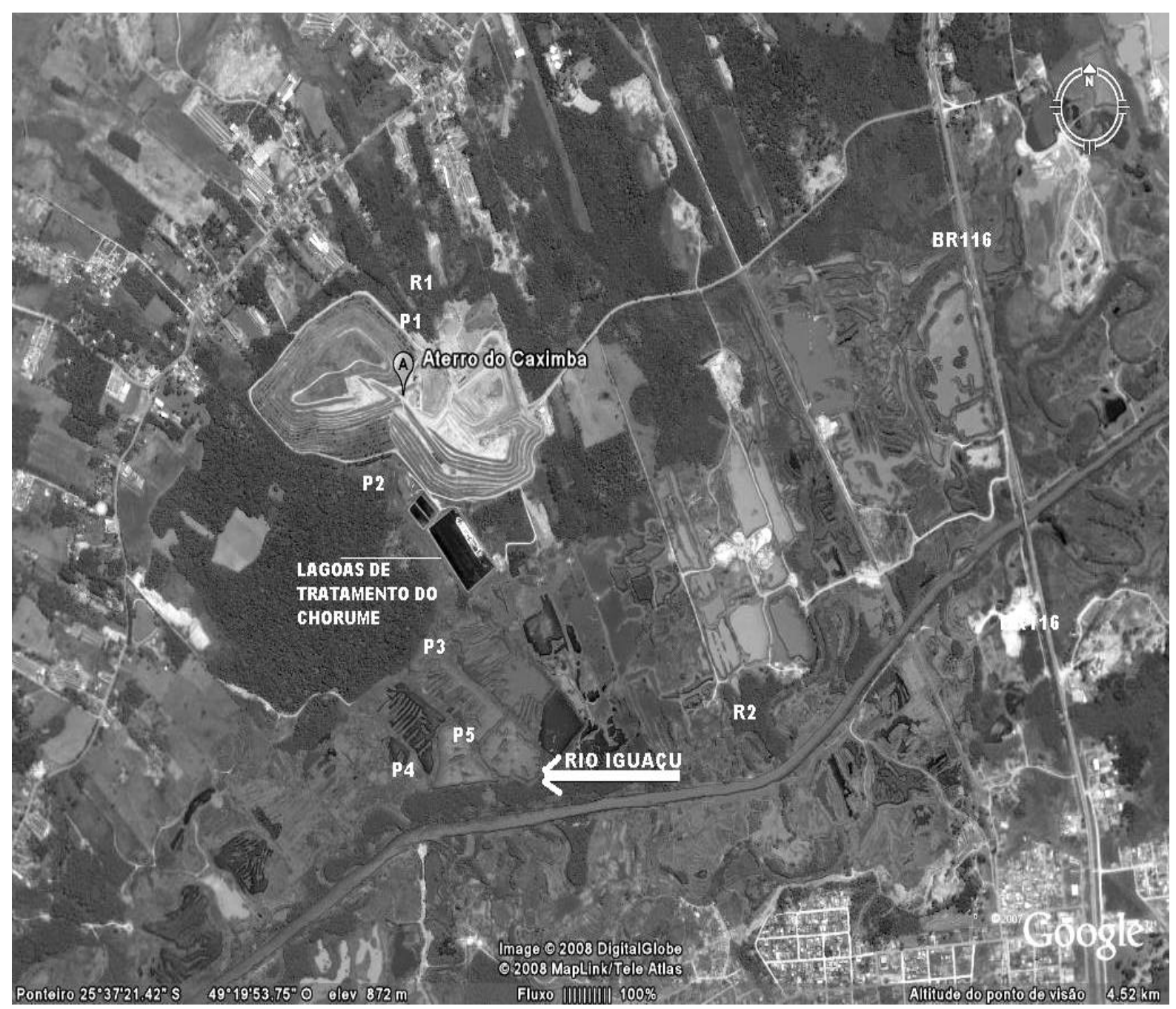

FIGURA 1 - Imagem de satélite (GeoEye) com os pontos de amostragem dos solos no entorno do Aterro Sanitário da Caximba (13 nov 2007).

\section{RESULTADOS E DISCUSSÃO}

\section{Características gerais dos solos}

Os solos desenvolvidos de granito/gnaisse são de textura argilosa (R1 e $\mathrm{P} 1)$ e textura média (P2) (Tabelas 1 e 2). Os solos desenvolvidos de sedimentos inconsolidados (P3, P4, P5 e R2) são de textura média a argilosa, com teores de argila variando de 300 a $720 \mathrm{~g} \mathrm{~kg}^{-1}$. Os sedimentos aluvionares holocênicos que ocorrem nas várzeas do Rio Iguaçu são constituídos predominantemente por argila e silte (MINEROPAR, 2004).

Os solos amostrados são de reação ácida (Tabela 2), o que favorece a disponibilidade e ação tóxica de metais pesados (Kabata Pendias \& Pendias, 2001). Em condições ácidas, o fenômeno de adsorção é mais importante no controle da biodisponibilidade de metais, enquanto que reações de solubilidade ou precipitação e complexação têm maior influência em condições neutras ou alcalinas dos solos (Sparks, 1995).

Os valores de CTC total dos solos foram altos (Tabela 2), conferindo-Ihes grande potencial na retenção de cátions, inclusive metais pesados (Sodré et al., 2001). Os altos valores de atividade da fração argila (valor T), iguais e superiores a $27 \mathrm{cmol}_{c}$ $\mathrm{dm}^{-3}$, em particular nas amostras do P2 (Tabela 2), são relacionados à presença de minerais filossilicatados do tipo 2:1, ou ainda, às concentrações expressivas de matéria orgânica (teor de carbono orgânica superior à $10 \mathrm{~g} \mathrm{~kg}^{-1}$, exceto no P2II).

As elevadas concentrações de bases trocáveis, $\mathrm{Ca}^{2+}, \mathrm{Mg}^{2+}, \mathrm{K}^{+}$e $\mathrm{Na}^{+}$, ocupando os sítios de troca dos Antropossolos, juntamente com o incremento nos teores de fósforo em alguns perfis (Tabela 2) podem ser atribuídos ao contato do chorume do aterro com os solos da várzea (Tabela 1).

As formas mal cristalizadas de $\mathrm{Fe}$ e $\mathrm{Al}$ apresentam alta superfície específica e elevada carga superficial dependente de $\mathrm{pH}$ (McKeague \& Day, 1966; Fontes et al., 2001), portanto maior capacidade de adsorção e retenção de metais pesados (Shuman, 1982). O material amorfo dissolvido pelo oxalato de amônio é constituído, 
TABELA 2 - Características químicas e teor de argila dos solos.

\begin{tabular}{|c|c|c|c|c|c|c|c|c|c|c|c|c|c|c|}
\hline Am. & Prof. & $\begin{array}{c}\mathrm{pH} \\
\mathrm{H}_{2} \mathrm{O}\end{array}$ & $\begin{array}{c}\mathrm{pH} \\
\mathrm{CaCl}_{2}\end{array}$ & $\mathrm{Al}^{3+}$ & $\begin{array}{c}\mathrm{H}^{+} \\
+ \\
\mathrm{Al}^{3+}\end{array}$ & $\mathrm{Ca}_{+}^{2}$ & $\mathrm{Mg}_{+}^{2}$ & $\mathrm{~K}^{+}$ & $\mathrm{Na}^{+}$ & $\begin{array}{l}\text { CTC } \\
\text { total }\end{array}$ & $\mathrm{CO}^{(1)}$ & $P$ & $\begin{array}{l}\mathrm{Ar} \\
(2)\end{array}$ & $T^{(3)}$ \\
\hline & $\mathrm{cm}$ & & & \multicolumn{7}{|c|}{$\mathrm{cmol}_{\mathrm{c}} \mathrm{kg}^{-1}$} & $\mathrm{~g} \mathrm{~kg}^{-1}$ & $\mathrm{mg} \mathrm{kg}^{-1}$ & \multicolumn{2}{|c|}{$\mathrm{g} \mathrm{kg}^{-1} \mathrm{cmol}_{\mathrm{ckg}} \mathrm{kg}^{-1}$} \\
\hline P1-I & $0-20$ & 6,0 & 5,1 & 0,1 & 3,7 & 6,5 & 5,0 & 0,4 & 0,3 & 16,0 & 30,5 & 6,2 & 490 & 32,7 \\
\hline P1-II & $20-$ & 5,5 & 4,6 & 0,3 & 4,5 & 7,5 & 4,0 & 0,1 & 0,2 & 16,4 & 17,8 & 4,4 & 540 & 30,3 \\
\hline P1-III & $40-$ & 5,8 & 4,8 & 0,1 & 4,9 & 9 & 5,5 & 0,1 & 0,1 & 19,6 & 17,2 & 2,0 & 520 & 37,8 \\
\hline P2-I & $0-20$ & 5,8 & 5,0 & 0,1 & 3,1 & 9,5 & 3,5 & 0,4 & 0,3 & 16,8 & 15,4 & 1,7 & 180 & 93,7 \\
\hline P2-II & $20-$ & 5,5 & 4,5 & 0,4 & 3,4 & 7,5 & 3,5 & 0,4 & 0,2 & 15,0 & 9,4 & 1,9 & 180 & 83,8 \\
\hline P2-III & $40-$ & 5,6 & 4,7 & 0,2 & 3,0 & 5,4 & 3,0 & 0,2 & 0,2 & 11,4 & 12,4 & 1,1 & 180 & 63,8 \\
\hline R1-I & $0-20$ & 4,6 & 3,8 & 4,3 & 13,1 & nd & 0,3 & 0.1 & 0,0 & 13,5 & 37,7 & 1,6 & 530 & 27,0 \\
\hline R1-II & $20-$ & 4,6 & 3,8 & 4,2 & 11,8 & nd & 0,1 & 0,0 & 0,0 & 11,9 & 27,5 & 0,5 & 520 & 26,9 \\
\hline R1-III & $40-$ & 4,5 & 3,7 & 4,3 & 10,3 & nd & 0,1 & 0,0 & 0,0 & 10,4 & 21,4 & 0,2 & 500 & 19.7 \\
\hline P3-I & $0-20$ & 6,4 & 5,6 & 1,3 & 2,5 & 4,0 & 6,0 & 2,4 & 1,1 & 16,1 & 10,6 & 12 & 300 & 53,7 \\
\hline P3-II & $20-$ & 5,5 & 5,0 & 0,2 & 6,4 & 6,0 & 7,0 & 3,2 & 1,5 & 24,2 & 37,7 & 5,9 & 520 & 46,5 \\
\hline P3-III & $40-$ & 5,5 & 5,0 & 0,1 & 5,2 & 4,0 & 3,0 & 1,6 & 1,0 & 14,8 & 35,5 & 5,6 & 360 & 41,2 \\
\hline P4-I & $0-20$ & 5,3 & 4,2 & 1,3 & 6,4 & 3,0 & 3,0 & 0,7 & 0,5 & 13,6 & 17,2 & 2,3 & 370 & 36,8 \\
\hline P4-II & $20-$ & 5,4 & 4,0 & 1,7 & 6,2 & 1,8 & 3,2 & 0,6 & 0,5 & 12,3 & 13,6 & 1,4 & 400 & 30,9 \\
\hline P4-III & $40-$ & 5,2 & 4,0 & 2,6 & 6,0 & 0,8 & 1,5 & 0,3 & 0,3 & 9,0 & 12,4 & 1,0 & 360 & 25,0 \\
\hline P5-I & $0-20$ & 5,0 & 3,9 & 0,5 & 5,7 & 4,9 & 3,3 & 1,3 & 0,8 & 16,0 & 23,2 & 3,4 & 430 & 37,2 \\
\hline P5-II & $20-$ & 5,7 & 5,2 & 0,1 & 5,0 & 4,5 & 3,0 & 1,9 & 1,2 & 15,6 & 14,2 & 3,9 & 580 & 27,0 \\
\hline P5-III & $40-$ & 5,6 & 5,3 & 0,1 & 6,2 & 7,5 & 4,5 & 2,9 & 1,5 & 22,6 & 34,1 & 3,5 & 720 & 31,5 \\
\hline R2-I & $0-20$ & 4,5 & 3,8 & 2,9 & 8,0 & 6,2 & 5,3 & 0,2 & 0,1 & 19,8 & 20,8 & 1,1 & 450 & 44,0 \\
\hline R2-II & $20-$ & 4,3 & 3,6 & 3,4 & 10,5 & 5,5 & 5,8 & 0,1 & 0,1 & 22,0 & 24,5 & 0,8 & 400 & 55,2 \\
\hline R2-III & 40- & 4,3 & 2,8 & 3,5 & 9,8 & 5,0 & 5,9 & 0,1 & 0,1 & 20,9 & 23,2 & 0,6 & 400 & 52,4 \\
\hline
\end{tabular}

(1) $\mathrm{CO}=$ carbono orgânico ${ }^{(2)} \mathrm{Ar}=\mathrm{Teor}$ de argila ${ }^{(3)} \mathrm{T}=$ Atividade da fração argila ou CTC da fração argila: CTC $\times 100 / \%$ argila (EMBRAPA, 1999b). nd = valores abaixo do nível de detecção do método analítico.

principalmente, por Fe, com menor participação de Al, com exceção do Cambissolo (R1) (Tabela 3). Valores superiores de Fe oxalato de amônio foram observados por outros autores em solos de ambientes hidromórficos (Wowk \& Melo, 2005; Lima et al., 2006). Os teores de $\mathrm{Fe}$ de óxidos mais cristalinos (ditionito-citrato bicarbonato) variaram de 20,9 a 52,3 $\mathrm{g} \mathrm{kg}^{-1}$ e de 39,0 a $39,7 \mathrm{~g} \mathrm{~kg}^{-1}$ para os Antropossolos e Cambissolo, respectivamente (Tabela 3 ). As baixas concentrações de Fe mais cristalinos, em todos os solos, justificam-se pelo baixo conteúdo de Fe nos materiais de origem. As condições de hidromorfismo presentes nos perfis P1, P2, P3, P4 e P5 (Tabela 1) também favoreceram a remoção do $\mathrm{Fe}^{2+}$ do pedoambiente. Para o Gleissolo (R2), apesar de apresentar o mesmo material de origem dos solos P3, P4 e P5, os teores de Fed foram ainda inferiores $\left(9,2\right.$ a $\left.13,0 \mathrm{~g} \mathrm{~kg}^{-1}\right)$ em razão do hidromorfismo mais intenso nesse solo de referência (Tabela 1). Em solos alagados, a ausência de oxigênio e a presença de compostos orgânicos criam condições para a redução de vários compostos: $\mathrm{NO}_{3}^{-}, \mathrm{Mn}^{4+}, \mathrm{Fe}^{3+}$, entre outros (Sparks, 1995; Rowell, 1981).

Os valores da relação Feo/Fed dos solos hidromórficos (P1, P2, P3, P4, P5 e R2) foram superiores aos observados para o Cambissolo (R1) (Tabela 3), uma vez que, o excesso de umidade favorece a formação de formas de ferro com menor grau de cristalinidade (Melo et al., 2001a; Wowk \& Melo, 2005). Em solos mais intemperizados e bem drenados é comum encontrar valores para a relação Feo/Fed inferiores a 0,01 (Fontes \& Weed, 1991; Melo et al., 2001b; Ghidin et al., 2006).

Dado os baixos teores de óxidos de $\mathrm{Fe}$ cristalinos (hematita e goethita) nos Antropossolos (P1, P2, P3, P4 e P5) (Tabela 4), espera-se baixo potencial de adsorção específica de metais pesados (complexos de esfera interna). A adsorção específica é importante devido ao forte caráter covalente da ligação entre o metal e o oxigênio da superfície destes óxidos (Fontes et al., 2001), o que reduz a possibilidade de contaminação dos aqüíferos. Os teores mais elevados de gibbsita no Cambissolo (R1) em relação aos demais solos estão relacionados às melhores condições de drenagem no local, associada à posição mais elevada no relevo, favorecendo a perda de sílica e de bases.

A fração argila dos solos é constituída principalmente por caulinita, com teores variando de 548,5 a $702,1 \mathrm{~g} \mathrm{~kg}^{-1}$ (Tabela 4). O grupo silanol (Si-O) presente na borda da superfície siloxana da caulinita permite a formação de cargas negativas mesmo em baixos valores de $\mathrm{pH}$ (TARI et al., 1999). O ponto de carga zero (PCZ) deste mineral é em torno de 4,0 (Sparks, 1995) e o pH dos Antropossolos amostrados é superior a 5,0 (Tabela 2), o que determina predomínio de cargas negativas na superfície da caulinita e favorece a adsorção de cátions.

A vermiculita com hidroxi entre camadas (VHE) (Figura 2) está presente em todos os solos, porém não foi quantificada (Tabela 4). Tem-se a expectativa de expressiva ocorrência desse 
ZANELLO, S. et al. Mineralogia e teores de cromo...

TABELA 3 - Teores de ferro e alumínio extraídos pelo oxalato de amônio ácido (Feo e Alo) e ditionito-citratobicarbonato (Fed e Ald) da fração argila.

\begin{tabular}{|c|c|c|c|c|c|c|c|c|}
\hline \multirow[b]{2}{*}{ Amostra } & \multicolumn{8}{|c|}{ Relação ao Total $^{(1)}$} \\
\hline & Prof. & Feo & Alo & Feo & Alo & Fed & Ald & Feo/Fed \\
\hline & $\mathrm{cm}$ & 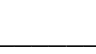 & & & & 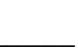 & & \\
\hline P1-I & $0-20$ & 4,7 & 0,4 & 91,7 & 8,3 & 21,8 & 3,8 & 0,216 \\
\hline P1-II & $20-40$ & 2,1 & 0,7 & 75,3 & 24,7 & 38,5 & 3,9 & 0,113 \\
\hline P1-III & $40-60$ & 4,5 & 0,9 & 83,3 & 16,7 & 38,6 & 5,1 & 0,178 \\
\hline P2-I & $0-20$ & 11,5 & 1,7 & 87,1 & 12,9 & 45,8 & 4,3 & 0,175 \\
\hline P2-II & $20-40$ & 8,4 & 2,4 & 77,9 & 22,1 & 45,0 & 5,1 & 0,395 \\
\hline P2-III & $40-60$ & 11,5 & 1,7 & 87,2 & 12,8 & 48,2 & 4,9 & 0,469 \\
\hline R1-I & $0-20$ & 1,7 & 1,7 & 49,0 & 51,0 & 39,7 & 11,6 & 0,348 \\
\hline R1-II & $20-40$ & 1,7 & 1,9 & 46,8 & 53,2 & 39,0 & 11,8 & 0,150 \\
\hline R1-III & $40-60$ & 2,1 & 2,1 & 49,8 & 50,2 & 39,1 & 12,1 & 0,162 \\
\hline P3-I & $0-20$ & 0,8 & 1,1 & 42,1 & 57,9 & 41,8 & 4,3 & 0,175 \\
\hline P3-II & $20-40$ & 7,8 & 2,0 & 79,4 & 20,6 & 26,7 & 3,5 & 0,244 \\
\hline P3-III & $40-60$ & 9,8 & 2,4 & 80,4 & 19,6 & 20,9 & 3,4 & 0,576 \\
\hline P4-I & $0-20$ & 5,9 & 2,5 & 70,1 & 29,9 & 32,9 & 4,3 & 0,703 \\
\hline P4-II & $20-40$ & 4,3 & 2,1 & 67,8 & 32,2 & 43,9 & 5,2 & 0,585 \\
\hline P4-III & $40-60$ & 7,1 & 2,4 & 74,8 & 25,2 & 39,5 & 5,1 & 0,398 \\
\hline P5-I & $0-20$ & 7,3 & 1,7 & 81,3 & 18,7 & 44,6 & 4,8 & 0,464 \\
\hline P5-II & $20-40$ & 6,9 & 2,0 & 77,8 & 22,2 & 52,3 & 4,7 & 0,352 \\
\hline P5-III & $40-60$ & 10,6 & 2,1 & 83,7 & 16,3 & 24,5 & 3,7 & 0,420 \\
\hline R2-I & $0-20$ & 5,4 & 1,5 & 77,8 & 22,2 & 9,2 & 2,3 & 0,557 \\
\hline R2-II & $20-40$ & 6,4 & 1,7 & 79,0 & 21,0 & 9,9 & 2,2 & 0,674 \\
\hline R2-III & $40-60$ & 6,6 & 1,5 & 81,2 & 18,8 & 13,0 & 2,1 & 0,762 \\
\hline
\end{tabular}

TABELA 4 - Composição mineralógica da fração argila de amostras dos solos ${ }^{(1)}$

\begin{tabular}{|c|c|c|c|c|c|c|c|c|}
\hline Amostra & Profundidade & Ct & $\mathrm{Gb}$ & Gt & $\mathrm{Hm}$ & $\begin{array}{c}\text { Material } \\
\text { amorfo }\end{array}$ & Total & VHE \\
\hline & $\mathrm{cm}$ & \multicolumn{6}{|c|}{$\mathrm{g} \mathrm{kg}^{-1}$} & \\
\hline P1-I & $0-20$ & 602,2 & 41,8 & 28,8 & 7,2 & 17,0 & 697,0 & $\mathrm{nq}$ \\
\hline P1-II & $20-40$ & 548,5 & 42,7 & 44,9 & 13,4 & 29,0 & 678,5 & nq \\
\hline P1-III & $40-60$ & 620,0 & 61,4 & 51,2 & 12,8 & 14,0 & 759,4 & nq \\
\hline P2-I & $0-20$ & 633,3 & 57,7 & 59,4 & 16,8 & 44,0 & 811,2 & nq \\
\hline P2-II & $20-40$ & 602,3 & 51,5 & 57,4 & 15,2 & 44,0 & 770,4 & $\mathrm{nq}$ \\
\hline P2-III & $40-60$ & 620,4 & 42,8 & 57,9 & 24,8 & 47,0 & 792,9 & nq \\
\hline R1-I & $0-20$ & 702,1 & 140,2 & 65,4 & 5,7 & 26,0 & 939,4 & $\mathrm{nq}$ \\
\hline R1-II & $20-40$ & 644,3 & 136,9 & 59,1 & 11,3 & 43,0 & 894,6 & $\mathrm{nq}$ \\
\hline R1-III & $40-60$ & 668,0 & 133,0 & 55,5 & 13,9 & 36,0 & 906,4 & nq \\
\hline P3-I & $0-20$ & 611,8 & 31,4 & 45,7 & 22,5 & 10,0 & 721,4 & nq \\
\hline P3-II & $20-40$ & 621,2 & 52,6 & 47,4 & $\mathrm{nq}$ & 50,0 & 771,2 & nq \\
\hline P3-III & $40-60$ & 661,2 & 53,5 & 36,7 & nq & 45,0 & 796,4 & nq \\
\hline P4-I & $0-20$ & 650,1 & 56,8 & 56,0 & $\mathrm{nq}$ & 43,0 & 805,9 & $\mathrm{nq}$ \\
\hline P4-II & $20-40$ & 645,2 & 49,0 & 76,5 & nq & 27,0 & 797,7 & nq \\
\hline P4-III & $40-60$ & 674,8 & 52,3 & 66,7 & nq & 36,0 & 829,8 & $\mathrm{nq}$ \\
\hline P5-I & $0-20$ & 633,4 & 41,2 & 62,3 & 13,7 & 38,0 & 788,6 & $\mathrm{nq}$ \\
\hline P5-II & $20-40$ & 607,2 & 48,0 & 87,4 & $\mathrm{nq}$ & 40,0 & 782,6 & $\mathrm{nq}$ \\
\hline P5-III & $40-60$ & 593,6 & 42,7 & 41,9 & nq & 55,0 & 733,2 & nq \\
\hline R2-I & $0-20$ & 700,7 & 54,2 & 14,7 & nq & 18,0 & 787,6 & nq \\
\hline R2-II & $20-40$ & 655,4 & 43,8 & 17,6 & nq & 20,0 & 736,8 & $\mathrm{nq}$ \\
\hline R2-III & $40-60$ & 652,4 & 42,3 & 13,6 & 6,4 & 20,0 & 734,7 & nq \\
\hline
\end{tabular}

(1) Ct (Caulinita) e Gb (Gibbsita) determinadas com base na perda de massa da amostra de argila por meio de análise termo gravimétrica (Jackson, 1979); Hm (hematita) e Gt (Goethita) quantificadas com base no teor de Fe extraído pelo DitionitoCitrato-Bicarbonato (DCB) e características obtidas por difratograma de raios-X (DRX) (Melo et al. 2001b); Material amorfo, determinado pela redução em peso da amostra pelo tratamento com oxalato de amônio [redução em massa da amostra = (peso inicial - peso final) x 1000 / peso inicial]. VHE, vermiculita com hidroxi entre camadas; nq - mineral apenas identificado por DRX (análise qualitativa). 


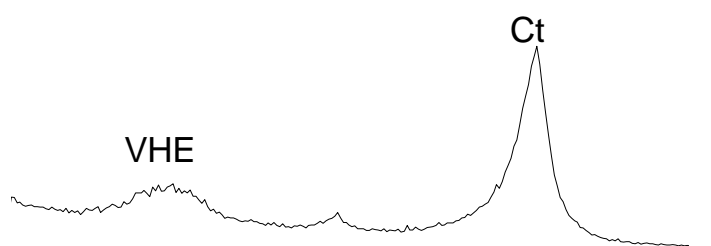

(A)

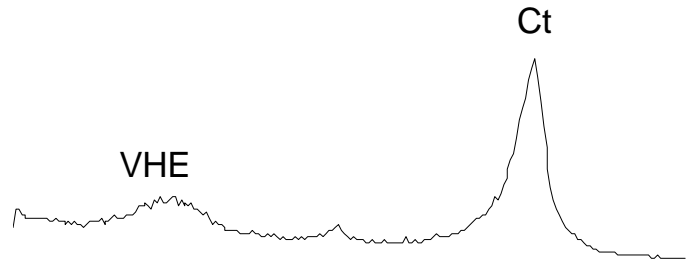

(B)

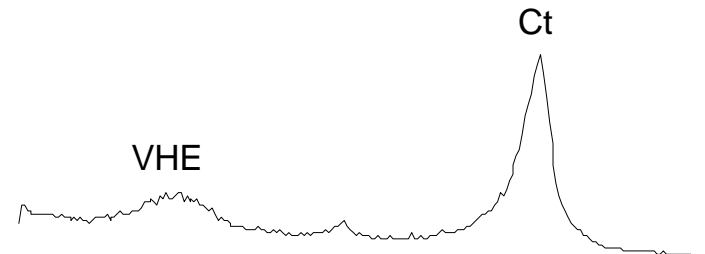

(C)

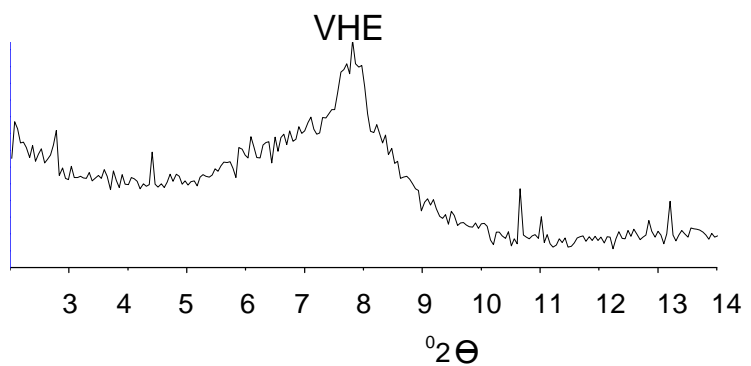

(D)

FIGURA 2 - Difratogramas de raios-x (radiação Cu-k $\alpha$ ) de amostras orientadas da fração argila desferrificada do Antropossolo (P3-II) ao serem submetidas aos tratamentos com Mg (A), Mg com etileno glicol (B), K (C) e aquecimento a $550{ }^{\circ} \mathrm{C}$ - destruição das ilhas de hidroxi e colapso do espaçamento basal do mineral $(1,4$ para $1,0 \mathrm{~nm})(\mathrm{D})$.

mineral nos solos, dada a diferença entre a soma de minerais da fração argila (média de $787,4 \mathrm{~g} \mathrm{~kg}^{-1}$ ) em relação a $1000 \mathrm{~g} \mathrm{~kg}^{-1}$ (Tabela 4) e elevados valores de CTC (Tabela 2 ) dos solos. A retenção de cátions metálicos na superfície de minerais 2:1, como o VHE, através de complexos de esfera externa, é majoritariamente reversível, rápida e influenciada pela força iônica da solução (Sparks, 1995).

\section{Teores de $\mathrm{Cr}, \mathrm{Ni}, \mathrm{Cu}, \mathrm{Zn}$ e $\mathrm{Pb}$ nas amostras de chorume e de solos}

Para a amostra $\mathrm{CH} 1$, referente ao chorume do emissário de líquidos percolados da Fase I do aterro sanitário, somente o $\mathrm{Pb}$ foi detectado, apresentando concentração de $1,25 \mathrm{mg} \mathrm{dm}^{3}$. Para a amostra $\mathrm{CH} 2$, somente o $\mathrm{Ni}$ foi detectado $(0,19$ $\mathrm{mg} \mathrm{dm}^{3}$ ) e, para a amostra $\mathrm{CH}$, não foram detectados metais pelo método analítico empregado. Morais (2005) analisou o chorume referente à Fase I do aterro em 2004 e detectou concentrações de $0,28 \mathrm{mg} \mathrm{dm}^{3} ; 0,36 \mathrm{mg} \mathrm{dm}^{3} ; 0,45$ $\mathrm{mg} \mathrm{dm} \mathrm{m}^{3} ; 1,06 \mathrm{mg} \mathrm{dm} \mathrm{m}^{3}$ e $1,43 \mathrm{mg} \mathrm{dm}{ }^{3}$ de $\mathrm{Pb}, \mathrm{Cu}, \mathrm{Cr}$, $\mathrm{Zn}$ e Ni, respectivamente. O autor atribuiu as baixas concentrações de metais ao $\mathrm{pH}$ alcalino do chorume (média de 8,1), o que contribui para a imobilização destes metais no aterro e no fundo das lagoas de tratamento: precipitação na forma de hidróxidos ou sulfetos; complexação pela matéria orgânica; etc. (Christensen et al., 2001; Jucá, 2003; Koh et al., 2004; SILVA et al., 2004).

Observou-se um incremento nos teores totais de metais no Antropossolo $\mathrm{P} 1$, em relação ao perfil de referência $R 1$, em todas as profundidades (Tabela 5). Dada a proximidade do local de amostragem com a borda da parte de superior do aterro (Figura 1 e Tabela 1), suspeita-se que houve comunicação subsuperficial entre o chorume do aterro da Fase I e o perfil P1.

De modo geral, o maior incremento dos teores totais de $\mathrm{Cr}, \mathrm{Ni}, \mathrm{Cu}, \mathrm{Zn}$ e $\mathrm{Pb}$, em relação ao perfil de referência $\mathrm{R} 2$, foram para os perfis $\mathrm{P} 3$ e P5 (Tabela 5), ambos sob influência direta do escorrimento do chorume na várzea em direção ao rio Iguaçu (Tabela 1). 
TABELA 5 - Teores totais e teores trocáveis de $\mathrm{Pb}, \mathrm{Cu}, \mathrm{Ni}, \mathrm{Cr}$ e $\mathrm{Zn}$ obtidos nas amostras de solos.

\begin{tabular}{|c|c|c|c|c|c|c|c|c|c|c|}
\hline \multirow{2}{*}{ Amostra } & \multicolumn{2}{|c|}{$\mathrm{Pb}$} & \multicolumn{2}{|c|}{$\mathrm{Cu}$} & \multicolumn{2}{|c|}{$\mathrm{Ni}$} & \multicolumn{2}{|c|}{$\mathrm{Cr}$} & \multicolumn{2}{|c|}{$\mathrm{Zn}$} \\
\hline & Total & Trocável & Total & Trocável & Total & Trocável & Total & Trocável & Total & Trocáve \\
\hline & & & & & $\mathrm{mg}$ & & & & & \\
\hline P1-I & 28,1 & 14,0 & 37,9 & nd & 56,3 & nd & 92,9 & nd & 118,8 & 6,1 \\
\hline P1-II & 74,2 & 9,1 & 31,9 & nd & 43,0 & nd & 52,9 & nd & 119,6 & 5,3 \\
\hline P1-III & 51,2 & 6,7 & 29,8 & nd & 39,4 & nd & 37,2 & nd & 83,3 & 1,9 \\
\hline P2-I & nd & nd & 33,4 & nd & 59,9 & nd & 88,8 & nd & 103,2 & 0,5 \\
\hline P2-II & nd & nd & 33,4 & nd & 83,2 & nd & 91,6 & nd & 108,8 & 1,5 \\
\hline P2-III & 20,4 & nd & 37,2 & nd & 65,1 & nd & 82,3 & nd & 71,0 & 1,5 \\
\hline R1-I & 3,2 & 1,2 & 17,9 & nd & 23,7 & nd & 35,8 & nd & 36,3 & nd \\
\hline R1-II & 7,2 & nd & 16,9 & nd & 18,9 & nd & 15,2 & nd & 31,3 & nd \\
\hline R1-III & nd & nd & 16,9 & nd & 17,5 & nd & 12,2 & nd & 32,4 & nd \\
\hline P3-I & 30,9 & 1,7 & 37,0 & nd & 48,7 & nd & 79,8 & nd & 90,0 & nd \\
\hline P3-II & 16,0 & 6,9 & 40,7 & nd & 55,9 & nd & 88,7 & nd & 128,4 & 14,2 \\
\hline P3-III & 24,1 & 0,1 & 18,9 & nd & 32,3 & nd & 44,1 & nd & 70,4 & 7,9 \\
\hline P4-I & 14,0 & 4,5 & 12,9 & nd & 28,4 & nd & 37,0 & nd & 42,4 & 1,7 \\
\hline P4-II & 25,1 & nd & 8,0 & nd & 20,5 & nd & 37,1 & nd & 36,9 & 0,2 \\
\hline P4-III & 22,5 & 2,6 & 13,2 & nd & 23,0 & nd & 32,8 & nd & 46,8 & 0,1 \\
\hline P5-I & 53,5 & 6,0 & 18,7 & nd & 36,0 & nd & 38,9 & nd & 66,8 & 5,1 \\
\hline P5-II & 58,3 & nd & 14,0 & nd & 28,3 & nd & 41,4 & nd & 61,8 & 4,9 \\
\hline P5-III & 38,5 & nd & 26,0 & nd & 22,6 & nd & 63,6 & nd & 121,7 & 13,6 \\
\hline R2-I & 32,3 & 2,1 & 23,7 & nd & 47,5 & nd & 28,3 & nd & 72,7 & 11,4 \\
\hline R2-II & 25,6 & 2,4 & 15,6 & nd & 24,6 & nd & 33,0 & nd & 67,9 & 13,2 \\
\hline R2-III & 28,4 & nd & 14,7 & nd & 30,9 & nd & 27,5 & nd & 55,3 & 14,4 \\
\hline
\end{tabular}

Dada a falta de valores de segurança para concentração de metais pesados para os solos do Paraná, optou-se por utilizar os valores preconizados pela CETESB (2005) como referência para o presente trabalho. Os teores totais encontrados para os metais $\mathrm{Cr}$ e $\mathrm{Ni}$, estão em concentrações superiores aos valores de prevenção, $75 \mathrm{mg} \mathrm{kg}^{-1}$ e $30 \mathrm{mg} \mathrm{kg}^{-1}$, respectivamente, nos perfis P1, P2 e P3 (Tabela 5). Para o Zn, estes teores foram superiores aos valores de referência de qualidade (CETESB, 2005), porém, inferiores aos de prevenção. Os teores totais de $\mathrm{Pb}$ e $\mathrm{Cu}$ analisados, estão dentro dos parâmetros de qualidade para solos. Cabe citar que o perfil de referência R2, com teores totais de metais pesados superiores aos valores encontrados em algumas das amostras dos antropossolos, apesar de situar-se a montante da área de influência do chorume (Figura 1 e Tabela 1), possivelmente esteja sofrendo contaminação pelas águas do rio Iguaçu em épocas de cheias.

A concentração de $\mathrm{Cu}, \mathrm{Ni}$ e $\mathrm{Cr}$ trocáveis também foi baixa, ao ponto de não ser detectada pelo método analítico empregado (Tabela 5). A grande diferença entre os teores totais e trocáveis, se deve a formas mais estáveis dos metais, preferencialmente, nas formas estruturais e adsorvidas especificamente.

Ainda na fração trocável, para o Antropossolo $\mathrm{P} 1$, o $\mathrm{Pb}$ aparece em concentrações superiores às do perfil de referência $\mathrm{R} 1$, o que confirma o incremento deste metal no solo. Segundo Alloway (1993) não é comum encontrar Pb nas formas solúvel e trocável nos solos e sedimentos, a não ser em caso de contaminação recente, pois o $\mathrm{Pb}^{2+}$, após ser adicionado aos solos, leva em média de
24 a $48 \mathrm{~h}$ para ser imobilizado fortemente pelos colóides do solo.

Mesmo com as amostras dos solos apresentando diferentes características químicas (Tabela 2) e mineralógicas (Tabelas 3 e 4), os coeficientes de correlação simples de Pearson entre os teores totais e trocáveis de metais e CTC total, atividade da fração argila, carbono orgânico e teores dos minerais da fração argila, foram baixos e não significativos.

Dos metais estudados, o Ni e o Zn são os mais móveis no solo (Kabata Pendias \& Pendias, 2001), sendo que os valores de $\mathrm{pH}$ devem exceder 6,5 , a fim de minimizar a mobilidade e a toxicidade dos metais pesados nos solos (Alloway, 1993; Kabata Pendias \& Pendias, 2001), o que não se verifica nos solos no entorno do Aterro Sanitário da Caximba (Tabela 2). Segundo Sparks (1995), outro fator que pode influenciar a atividade dos metais pesados na solução do solo é o efeito da concentração total de eletrólitos, pois os altos teores de $\mathrm{Ca}^{2+}$ e $\mathrm{Mg}^{2+}$, principalmente nos Antropossolos P1, P2 e P3 (Tabela 2), podem estar contribuindo para a lixiviação daqueles metais pela competição entre os cátions pelos sítios de adsorção. Segundo Morais et al. (2006) o chorume do Aterro Sanitário da Caximba apresenta concentrações elevadas de $\mathrm{Ca}, \mathrm{Mg}, \mathrm{Na}, \mathrm{K}$ e Fe.

\section{CONCLUSÕES}

1) As amostras dos solos sob influência do chorume do Aterro Sanitário da Caximba apresentaram alta capacidade adsortiva de metais pesados: elevados valores de CTC total e atividade da fração argila, altos teores de argila, com 
predominância de caulinita e ocorrência de vermiculita com hidróxi entre camadas. Contudo não se observou relação direta entre essas características e teores de metais pesados nos solos.

2) De maneira geral, verificou-se incremento nos teores de metais pesados nos solos do entorno do aterro sanitário. Contudo, o nível de contaminação desses solos não foi muito expressivo, com base nos teores totais e trocáveis dos metais, devido a um ou mais dos seguintes fatores: (i) baixos teores de metais pesados no chorume; (ii) solos hidromórficos, o que permite a comunicação direta do chorume com a água do nível hidrostático; (iii) altos teores de cátions divalentes e trivalentes $\left(\mathrm{Ca}^{2+}\right.$, $\mathrm{Mg}^{2+}$ e $\mathrm{Al}^{3+}$ ) saturando as cargas negativas das argilas e da matéria orgânica, o que dificulta a adsorção dos metais pesados adicionados ao solo via chorume; e (iv) solos com valores de $\mathrm{pH}$ inferiores a 6,0, o que favorece a mobilização e a lixiviação dos metais.

\section{REFERÊNCIAS}

1. ALLOWAY, B. J. Heavy metals in soils. Glasgow: Blackie Academic \& Professional, 1995. 368 p.

2. COMPANHIA DE TECNOLOGIA DE SANEAMENTO AMBIENTAL (CETESB). Decisão de Diretoria no 195-2005 E. 2005. Disponível em: <http://www.cetesb.sp.gov.br/Solo/relatorios/tabela valores_2005.pdf>. Acesso em: 10/10/ 2008.

3. CHRISTENSEN, T. et al. Biogeochemistry of landfill leachates plumes. Applied Geochemistry. v. 16, n. 7-8, p. 659718, 2001.

4. CURCIO, G. R; LIMA, V. C.; GIAROLA, N. F. B. Antropossolos: proposta de ordem (1a aproximação). Colombo: Embrapa Florestas, 2004. 49 p.

5. EMPRESA BRASILEIRA DE PESQUISA AGROPECUÁRIA (EMBRAPA). Manual de métodos de análise de solo. 2. ed. Rio de Janeiro: EMBRAPA-CNPS, 1997.212 p.

6. EMPRESA BRASILEIRA DE PESQUISA AGROPECUÁRIA (EMBRAPA). - Centro Nacional de Pesquisa de Solos. Sistema brasileiro de classificação de solos. Brasília: Serviço de Produção de Informação; Rio de Janeiro: Embrapa Solos, 1999a. $412 \mathrm{p}$.

7. SILVA, F. C. (Org.). Manual de análises químicas de solos, plantas e fertilizantes. Brasília: Embrapa Comunicação para Transferência de Tecnologia, 1999b. 370 p.

8. FONTES, M. P. F.; WEED, S. B. Iron oxides in selected brazilian Oxisols. I. Mineralogy. Soil Science Society of American Journal, v. 55 , n. 4, p. 1143-1149, 1991

9. FONTES, M. P. F.; CAMARGO, O. A.; SPOSITO, G. Eletroquímica das partículas coloidais e sua relação com a mineralogia de solos altamente intemperizados. Scientia Agrícola, v. 58, n. 3, p. 627-646, 2001.

10. GEE, G. W.; BAUDER, J. W. Particle-size analysis. In: KLUTE, A. (Ed.). Methods of soil analysis. 2. ed. Madison: American Society of Agronomy, 1986. p. 383-412.

11. GHIDIN, A. A. et al. Toposseqüências de latossolos originados de rochas basálticas no Paraná. I-Mineralogia da fração argila. Revista Brasileira de Ciência do Solo, v. 30, n. 2, p. 293-306, 2006.

12. GOMES, P. C. et al. Extração fracionada de metais pesados em Latossolo Vermelho Amarelo. Revista Brasileira de Ciência do Solo, v. 21, n. 4, p.543-551, 1997.

13. JACKSON, M. L. Soil chemical analysis - advanced course. Madison: Prentice Hall, 1979. 895 p.

14. JENSEN, D. L.; LEDIN, A.; CHRISTENSEN, T. H. Speciation of heavy metals in landfill-leachate polluted groundwater. Water Research. v. 33, n. 11, p. 2642-2650, 1999

15. JUCÁ, J. F.T. destino final de los residuos sólidos en Brasil: situación actual e perspectivas. Resíduos, v. 72, n. 72 , p. 58-66, 2003.

16. KABATA-PENDIAS, A.; PENDIAS, H. Trace elements in soils and plants. 3. ed. Boca Raton: CRC Press, 2001. $413 \mathrm{p}$.

17. $\mathrm{KOH}, \mathrm{O}$. et al. Leachate treatment by the combination of photochemical oxidation with biological process. Journal of Photochemistry and Photobiology. v. 162, n. 2-3, p. 261-271, 2004.

18. KUNZE, G. W.; DIXON, J. B. Pretreatment for mineralogical analysis. In: KLUTE, A. (Ed.). Methods of soil analysis. 2. ed. Madison: American Society of Agronomy, 1986. p. 91-100.

19. LIM, C. H.; JACKSON, M. L. Dissolution for total elemental analysis. In: PAGE, A. L. (Ed.). Methods of soil analysis. Part 2: Chemical an microbiological properties. Madison: American Society of Agronomy, 1986. p. 1-12.

20. LIMA, H. N. et al. Mineralogia e química de três solos de uma toposseqüência da bacia sedimentar do Alto Solimões, Amazônia ocidental, Revista Brasileira de Ciência do Solo, v. 30, n. 1, p. 59-68, 2006.

21. LOPEZ, A. et al. Fenton's pre-treatment of mature landfill leachate. Chemosphere. v. 54, n. 7, p. 1005-1010, 2004.

22. McKEAGUE, J. A. Manual on soil sampling and methods of analysis. Otawa Canadian: Society of Soil Science, 1978. $212 \mathrm{p}$

23. McKEAGUE, J. A.; DAY, J. H. D. Dithionite and oxalate-extractable $\mathrm{Fe}$ and $\mathrm{Al}$ as aids in differentiating various classes of soils. Canadian Journal of Soil Science, v. 46, p. 13-22, 1966.

24. MEHRA, O. P.; JACKSON, M. L. Iron oxide removal from soils and clays by a dithionite-citrate system buffered with sodium bicarbonate. Clays Clay Mineralogy, v. 7, p. 317-327, 1960.

25. MELO, V. F. et al. Chemical and mineralogical properties of kaolinite - rich Brazilian soils. Soil Science Society of America Journal, v. 65 , p. 1.324-1.333, 2001a

26. MELO, V. F. et al. Características dos óxidos de ferro e de alumínio de diferentes classes de solo. Revista Brasileira de Ciência do Solo, v. 25, p. 19-32, 2001b.

27. MINERAIS DO PARANÁ (MINEROPAR). Atlas geológico do estado do Paraná. Curitiba, 2004. 1 CD-ROM. 
28. MINISTÉRIO PÚBLICO DO ESTADO DO PARANÁ (MP-PR). Procuradoria-Geral de Justiça. Assessoria de imprensa. IAP só libera caximba com o aval do MP. Disponível em: <http://celepar7cta.pr.gov.br/mppr/noticiamp.nsf/ 9401e882a180c9bc03256d790046d022/e490c8f09f613bf303256e910052b3b4?OpenDocument> Acesso em: 28/ $11 / 2004$

29. MORAIS, J. L. de. Estudo da potencialidade de processos oxidativos avançados, isolados e integrados com processos biológicos tradicionais, para tratamento de chorume de aterro sanitário. 2005. $207 \mathrm{f}$. Tese (Doutorado em Química) - Curso de Pós-Graduação em Química, Setor de Ciências Exatas, Universidade Federal do Paraná, Curitiba, 2005.

30. MORAIS, J. L. de; SIRTORI, C.; ZAMORA, P. P. Tratamento de chorume de aterro sanitário por fotocatálise heterogênea integrada a processo biológico convencional. Química Nova, v. 29, n. 1, p. 20-23, 2006.

31. NAIDU, R.; SUMNER, M. E.; HARTER, R. D. Sorption of heavy metals in strongly weathered soils: an overview. Environmental Geochemical and Health, v. 20, n. 1, p. 5-9, 1998.

32. ROWELL, D. L. Oxidation and reduction. In: GREENLAND, D. J.; HAYES, M. H. B. (Ed.). The chemistry of soil processes. Chichester: Wiley, 1981. p. 401-461.

33. SHUMAN, L. M. Separating soil iron and manganese-oxide fractions for microelement analysis. Soil Science Society of America Journal, v. 46, n. 5, p. 1099-1102, 1982.

34. SILVA, A. C.; DEZOTTI, M.; SANT'ANNA JR, G. L. Treatment and detoxification of a sanitary landfill leachate. Chemosphere, v. 55, n. 2, p. 207-214, 2004.

35. SODRÉ, F. F.; LENZI, E.; COSTA, A. C. S. da Utilização de modelos físico-químicos de adsorção no estudo do comportamento do cobre em solos argilosos. Química Nova, v. 24, n. 3, p. 324-330, 2001.

36. SPARKS, D. L. Environmental soil chemistry. San Diego: Academic Press, 1995. 267 p.

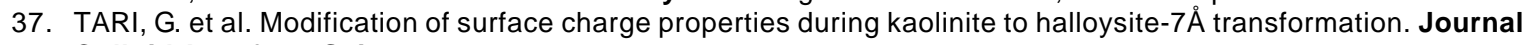
Colloid Interface Science, v. 210, n. 2, p. 360-366, 1999.

38. UNIVERSIDADE FEDERAL DO PARANÁ - UFPR. Manual de diagnóstico da fertilidade e manejo dos solos agrícolas. 2. ed. rev. e ampl. Curitiba: Departamento de Solos e Sngenharia Agrícola, 2003. $143 \mathrm{p}$.

39. WHITTIG, L. D.; ALLARDICE, W. R. X-Ray diffraction techniques. In: KLUTE, A. (Ed.). Methods of soil analysis. Madison: American Society of Agronomy. part 1. 1986, p. 331-362.

40. WOWK, G. I. T.; MELO, V. F. Avaliação do nível de chumbo, em solo de várzea, proveniente da reciclagem de baterias. Revista Brasileira de Engenharia Agrícola Ambiental, v. 9, n. 4, p. 613-622, 2005.

Recebido em 19/02/2008 Aceito em 01/10/2008 